\title{
СПЕЦИФИКА ГУМАНИТАРНОЙ ТЕОРИИ
}

\begin{abstract}
А.И. Афанасьев
В методологической литературе под теорией обычно понимают определенную систему подтвержденного знания, объясняющую некоторую совокупность явлений. В достаточно сложной структуре теории в первую очередь выделяют несколько обязательных компонентов, совокупность которых и делает данное знание теорией.

Чаще всего к ним относят: 1) исходные принципы, без которых невозможна организация теории и в качестве которых выступают постулаты, аксиомы, теоретические допущения, и даже отдельные законы, определенным образом высвечивающие эмпирический базис теории; 2) идеализированные объекты, которые отличают теорию, к примеру, от эмпирического знания; 3) совокупность законов и выводимых из них утверждений, образующих «тело» теории и выражаемых в некотором перечне понятий, составляющих ее язык и основные смыслыконцептуальное поле. Обращают внимание также на сферу применимости и сферу предсказания, которые связывают с технологическим воплощением теории, и на объект и предмет теории. Иногда специально выделяют концептуальную схему теории - ее ключевые смыслы, ответственные за понимание объекта и предмета. Часто подчеркивают, что в теории присутствует логика, по правилам которой выводятся следствия и одни утверждения из других. Но этот логический аппарат не всегда фиксируется в явном виде, поскольку им может быть не только специальный логико-математический аппарат, но и логика обыденного языка $[5$, с. 62]. Считается, что перечисленных признаков достаточно, чтобы систему знаний назвать теорией.

Указанные компоненты выделялись при анализе естественнонаучного знания и порой служили аргументом против попыток квалифици-
\end{abstract}

Актуальні проблеми духовності

(Відп. ред.: Я.В. Шрамко)

Кривий Pir (2008), 24-33 
ровать гуманитарное знание как теории или для противопоставления естественных и гуманитарных наук и их методов. Между тем можно показать, что гуманитарные теории соответствуют вышеперечисленным признакам, хотя и имеют специфические особенности. Обоснование данного утверждения и является целью статьи.

Исходные принципы теории позволяют систематизировать эмпирический материал, строить систему понятий и законов, поэтому их еще называют системообразующими признаками. Это могут быть аксиомы в математических и логических теориях, фундаментальные законы в теории Ньютона, уравнения Шредингера в квантовой механике, законы Кирхгофа в теории әлектрических цепей и т. д. В гуманитарньх науках соответствуюшие принципы также служат способом организации изучаемого материала в систему. Так, в исторических науках аграрные законы Рима могут служить основой упорядочивания событий римской истории. В других теориях в основу истории Рима положено римское право, в-третьих - классовые противоречия. О роли исходных принципов в теориях литературоведения свидетельствует дискуссия, развернувшаяся между символистами и формалистами в начале ХХ в. в России. Подход, идущий от А. Потебни и поддерживаемый А. Белым, А. Блоком, В. Ивановым, основывался на принципе, гласящем, что поэзия есть мышление образами. При таком подходе звуки стиха выступали чем-то второстепенным, и нужно было искать то, что за ними стояло, в частности, истолковывать смыслы образов. Подход формалистов в лице Б. Эйхенбаума, О. Брика, Л. Якубинского и др. основывался на принципе, утверждавшем самостоятельную роль и самоценность звуков в стихах. Благодаря этому теория формалистов совершенно иначе выделяла и истолковывала стихотворный и прозаический материал. Из нее следовало, что словесное искусство должно изучаться в его специфических чертах и что для этого необходимо исходить из различных функций поэтического и прозаического языка. На данной основе были обнаружены ритмико-синтаксические фигуры. Теория стиха становилась на путь разработки ритма как конструктивной основы стиха, разрабатывалась проблема конструкции художественного произведения. В связи с этим даже литературные произведения получали новое видение. Б. Эйхенбаум, например, писал:

В связи с вопросом о конструкщии новеллы была написана и моя статья «Как сделана „Шинель" Гоголя», ставящая рядом с проблемой сюжета проблему сказа - проблему конструкции на основе повествовательной манеры рассказчика. В статье этой я старался показать, что гоголевский текст «слагается из живых 
речевых представлений и речевых эмопий», что слова и предложения, выбираются и сдепляются у Гоголя по принщину выразительного сказа, при котором особенная роль приналлежит артикулящии, мимике, звуковым жестам и т. д. С этой точки зрения разобрана композищия «Шинели», построенная на смене комического сказа (с анекдотами, каламбурами и пр.) сентиментально - мелодраматической декламащией и придающая повести характер гротеска. В связи с этим конең «Шинели» трактуется как апофеоз гротеска - нечто вроде немой спены «Ревизора». Традищионные рассуждения о «романтизме» и «реализме» Гоголя оказывались ненужными и ничего не уясняющими $[10$, с.375$408]$.

Аналогичным образом поступает историк, пытаясь осмыслить некоторый документ, исходя только из знания существовавших в то время, допустим, экономических отношений. Он знает о них из других документов, с помощью которых он упорядочивает многообразие фактов и представляет его в виде некоторой целостности, основанной на определенных принципах. Иными словами, исходя из определенных принципов, он конструирует теорию, которая позволяет ему объяснить документ, и потом с помощью понятого таким образом документа рассмотреть и объяснить факты. «Историк на самом деле работает так же, как естествоиспытатель. Ведь и здесь и там каждый отдельный факт может быть увиден только в свете теории. Он „зависит от теории“. А теория, следовательно, является ,условием возмокного познания"» $[9$, с. 254].

Идеальные теоретические объекты-идеализации или конструкты - являются отличительным признаком науки любого предметного содержания. С их помошью осуществляется моделирование исследуемой реальности. Идеализированные объекты классической теории представляют собой, с одной стороны, упрощение исследуемого объекта, игнорирование многих реальных связей и отношений, но, с другой стороны, и его «доводку до идеала» в процессе создания теории. Как инструменты духовного освоения мира они образуют особого рода реальность объективированных мыслительных форм, которая, будучи онтологически вторичной, тем не менее, также обладает объективностью, так сказать «второго порядка» - объективностью проективноконструктивной деятельности человека, точнее интерсубъективностью в пределах данного научного сообщества. В естественных науках это «идеальный газ», «абсолютно черное тело» и др. В гуманитарных науках это «гештальт» в гештальтпсихологии, «общественно-экономи- 
ческая формация» К. Маркса, «идеальные типы» М. Вебера. Специфика конструктов в гуманитарных теориях состоит в том, что они не столь общезначимы как в естествознании и ограничены определенной школой или последователями некоторого направления, из-за чего часто связаны с именем автора. Однако их теоретическая эффективность не меньше, чем в естественнонаучных теориях. Они позволяют конструировать, организовывать исследуемую историческую, психологическую, социально-историческую реальность, способствуя объъдинению разрозненных явлений в целостную мыслительную картину и в әтом контексте изучать отдельные феномены. Вебер, например, выделяет две идеальнотипические организации экономического поведения: традиционную и целерациональную. Преодоление традиционализма связано с развитием современной рациональной капиталистической экономики, которая предполагает наличие определённых типов социальных отношений и определённых форм социального порядка. Несмотря на то, что сам Вебер пытался уйти от диктата естественнонаучных идеалов, доказывая гуманитарный характер социологии, тем не менее аналогия теоретических конструктов в естественнонаучных и гуманитарных теориях довольно прозрачна. Относительно идеальных объектов гуманитарной теории следует помнить, что им особенно опасно придавать онтологический статус. Между тем, люди нередко действуют так, будто әти конструкции и есть реальный мир, а ее идеализированные объекты - реальные связи и отношения самой действительности, что ведет к насаждению утопий в социально-политической практике. Поэтому желателен тщательный учет многообразных возможных следствий идеализаций, которые могут не совпадать с декларируемыми.

Теории в естественных науках помимо прочего имеют своей целью объяснение определенного класса природных явлений. Это осуществляется с помощью широкой системы естественных законов. Применительно к гуманитарным наукам о теориях можно сказать то же самое. Вместо законов природы здесь выступают правила и нормы из определенной области знания, например, из римского права в исторических теориях, которые также служат объяснению определенного класса исторических, психологических, литературных явлений. В то же время в гуманитарных теориях объяснение может осуществляться через специфические повествовательные структуры, включенные в описательные и объяснительные процедуры, например, нарративы. Даже если не соглашаться с идеей Ж.Ф.Лиотара о замене объяснительных теорий нарративами, следует признать присутствие нарра- 
тивных структур не только в литературе, но и во многих, если не во всех, научных теориях, что порой осмысливается как проявление нарративной рациональности и осознается как нарративный поворот в эпистемологии.

Среди отличительных черт нарратива обычно отмечают наличие конечной цели повествования, из которой все упоминаемые события получают объяснение; отбор нанболее важных событий, непосредственно относящихся к конечной цели и упорядочивание событий в определенную временную последовательность - осюжечивание. Нарративы участвуют в объяснительных процессах как минимум в трех случаях: 1) когда сам нарратив выступает объяснением; 2) когда нарратив в качестве лингвистической структуры неявно присутствует в объяснении; 3) когда объясняющая теория транслируется в культуре [1, c. 357]. Вообще в нарративном объяснении событие или явление характеризуются путем указания на его роль и значение в связи с определенной целью, проектом или некоторой целостностью, иными словами, проясняется его значение, вытекающее из последовавших за ним других событий, результатов, последствий. Например, историк пытается выстроить повествование так, чтобы события, а также действия персонажей были понятны вне зависимости от того, какой промежуток времени отделяет читателя от происходящих в истории событий. Причем, чем длиннее этот промежуток, тем более непонятными кажутся давние события. Они выглядят странными, загадочными, таинственными в основном из-за своей укорененности в древних способах жизни, отличных от наших. Историк придает смысл древним событиям, описывая их в категориальных формах культуры, таких как философские понятия, религиозные верования, нравственные нормы, формы повествований. В результате прошлое представляется как реальность, продолжением которой является современность. Немаловажно, что выделяются наиболее «важные» и исключаются «ненужные» события, исходя из цели повествования, выбирается определенный стиль и точка зрения, словно формируется сюжет художественного произведения, автором которого и одновременно субъектом объяснения выступает историк.

В гуманитарньх дисциплинах нарративные объяснения выступают важнейшим способом перехода на теоретический уровень организации знания, обеспечивая целостность, непротиворечивость, систематичность и другие характеристики теории. Например, они придают смысл человеческим действиям, представляя их как закономерные связи и отношения. Этому служат понятия, образуюшие повествовательную схему: цели, мотивы, интенции, препятствия, непредвиден- 
ные обстоятельства и т. п. Благодаря им несвязанные и независимые предметы, явления и события рассматриваются как связанные элементы целого. В объяснениях деятельности социальных групп и народов нарративы демонстрируют взаимосвязанность, закономерность, значимость разнообразных несвязанных, случайных, незначительных дел и событий, увязывая их в целостные образования. Индивидуальная жизнь как единый и целостный феномен не распадается на бесконечное множество самостоятельных событий и явлений, а объясняется с помощью автобиографического или биографического нарратива, выстраивающего четкую сюжетную линию. По-видимому, нарратив составляет фундаментальную психологическую, лингвистическую и социокультурную основу нашего объяснения мира.

В естественных науках также достаточно очевидна локальность производства и трансляции знания с использованием различных риторических приемов и повествовательных схем учеными, чтобы придать своим научным результатам вид объективных, трансцендентальных, вневременных и универсальных истин. Так «Оптика» Ньютона использовала принципы построения и терминологию работ Эвклида, заимствуя их риторическую силу, хотя содержала только описания әкспериментов и их результатов [8, с. 53].

Объяснительную силу имеют не только научные понятия и принципы, но и сама используемая субъектом структура научных текстов. Создается иллюзия, что тексты говорят как бы от имени природы, благодаря условной риторике и образцам научной речи, например, опусканию местоимений, использованию страдательного залога, беспристрастному тону и другим обязательным лингвистическим структурам, делающим научные тексты убедительными. В этом плане субъект расщепляется на автора и объясняющего. Автор объяснения, как обычный индивид со своей биографией, эмоциями, заблуждениями и т. П., отличается от «объяснителя», говорящего как бы от имени истины, хотя реально это одно и то же лицо. Справедливо отмечает Р. Барт: «Тот, кто говорит, - это не тот, кто пишет, а тот, кто пишет, это не тот, кто существует» $[7$, с. 221].

Среди понятий гуманитарных наук есть такие, которые просто именуют некоторый класс гуманитарных предметов, например, в литературоведении: «роман», «сказка», «сюжет» наподобие понятий «химический элемент», «молекула». Есть такие, которые соответствуют идеальным понятиям физики типа «сила тяготения», «гравитационное поле», «электромагнитная волна», - это, например, понятие «хронотоп» в литературоведении и культурологии. Причем понятия гуманитар- 
ных наук выполняют примерно те же функции, что и в других науках. Они обеспечивают определенное понимание изучаемых наукой объектов. При изменении понятийного аппарата меняется и видение объектов. Так, понятие «хронотоп», введенное в литературоведение и теорию культуры М.М. Бахтиным [2], существенно продвинуло изучение жанровой типологии романа и показало неприменимость к роману сюжетной модели, разработанной В.Я. Проппом для волшебной сказки, то есть способствовало выявлению принципиального отличия сказочного и романного текста $[6$, с. 326$]$.

Сферу применимости и сферу предсказания часто связывают с технологическим воплощением теории. М.Өпштейн показывает, что многие выдающиеся деятели культуры, например русского Серебряного века, Д. Мережковский, В. Иванов, А. Белый были не только писателями и теоретиками, но и раздвигали границы литературы, открывали в ней новую эпоху, исходя из теоретического видения ее задач и возможностей, создавали программу и практику символизма как целостного культурного движения, в котором были и художественная, и теоретическая, и философская, и религиозная составляющие. В гуманитарной сфере есть место для проективно-трансформативной деятельности. Это, например, словарная, а в значительной мере и словообразовательная работа В. Даля, по-новому структурировавшая лексические запасы русского языка и прибавившая к нему около 14 тысяч собственно далевских новообразований; «воображаемая филология» В. Хлебникова, которая вылилась примерно в такое же число неологизмов и в эксперименты с морфологией и синтаксисом, значительно увеличившие гибкость русского языка; в наше время - «грамматология» Ж. Деррида, которая из теоретической сферы постоянно выходит на уровень трансформации языковых практик. Все это можно отнести к гуманитарным технологиям, т. е. практикам второго, надтеоретического, а не дотеоретического уровня [11].

В методологии науки часто различают объект и предмет теории. Среди авторов нет единства по поводу толкования этих терминов, в частности, одни называют предметом то, что другие называют объектом и наоборот [3]. Но, пожалуй, чаще встречается следующее словоупотребление, описанное Б.С.Дыниным: «Под предметом надо понимать материальное явление (луна, рассвет, огонь и т. п.), которое осознается человеком до и помимо применения им метода исследования... Под объектом теории надо понимать фиксированные при помощи знаковых систем свойства и отношения, которые выявляются в предмете в процессе его исследования посредством метода» $[4$, с.9]. K этому сле- 
дует добавить, что предметом может выступать не только материальное, но и идеальное явление, например, сама теория или концепция, или внутренний мир, чувства и мысли, скажем, автора литературного произведения или естественнонаучной теории.

Специфика гуманитарной теории состоит, в частности, в том, что она может создавать не только свой объект, но и свой предмет. Точнее участвовать в его создании вместе с другими дискурсами. В этом существенное отличие гуманитарной теории от естественнонаучной, которая хотя и конструирует свой объект, но не конструирует свой предмет. Природные (физические) предметы существуют сами по себе. Поэтому здесь возникает проблема соответствия теории предмету как проблема истинности. В гуманитарной теории и вообще в гуманитарном дискурсе, где могут присутствовать разные теории и не только теории, природный (физический) предмет не представлен, например автор литературного произведения или исторический персонаж как биологический организм или совокупность физических величин, поскольку это не важно. Обыденное сознание и здравый смысл еще могут соотносить Александра Пушкина как автора «Евгения Онегина» или Екатерину Вторую как основательницу Одессы с существовавшими в действительности людьми, благо их внешний вид и даже черты характера хорошо известны. Но в литературоведении автор «Евгения Онегина» как предмет, существующий объективно, представлен сложнейшей конструкцией, в которой природные данные этого курчавого мужчины не присутствуют. Здесь автор не имеет объема груди, роста, веса, длины носа, цвета глаз и т. д. Возможно в будущем возникнут дискурсы и теории, в которых будет прослежена связь указанных свойств с данным литературным произведением, но сейчас автор «Евгения Онегина» есть нечто другое. Это совокупность некоторых мыслей и чувств, как бы висящих в воздухе, поскольку не доказано, что они могут принадлежать исключительно кареглазым, а не голубоглазым, низкорослым, а не высокорослым, брюнетам, а не блондинам. Более того, тот фрагмент внутреннего мира автора, который ответственен за замысел и написание «Евгения Онегина», реконструирован на основе исторических, культурологических, психологических, литературоведческих и т. п. данных, которые в свою очередь являются конструкциями, сформированными историческими, культурологическими, психологическими дискурсами и теориями. Это и есть гуманитарный исторический или культурологический предмет в виде человека, точнее его внутреннего мира, текста, события, поступка, якобы существующих объективно. Объективными они могут считаться лишь для той тео- 
рии, которая на их основе сконструирует свой объект как аспект или модель данного предмета. Удачная теория может даже изменить представление о предмете, реконструировав его, что постоянно происходит в гуманитаристике, особенно в истории, требуя ее переписывания, и служит у профанов поводом для насмешек.

Разница между гуманитарным объектом и гуманитарным предметом состонт в том, что первый конструируется соответствующей теорией, а второй - многообразными теориями, концепциями, дискурсами и появляется, как правило, раньше первого. Поэтому об́ истинности гуманитарного описания - исторического, психологического, литературоведческого как соответствия предмету - говорить нельзя, за исключением особых случаев и особых теорий. Зато можно говорить об адекватности интерпретации в рамках соответствующего контекста, системы ценностей, теории и т. д. В этом смысле не только объект как аспект предмета создается гуманитарной теорией, но и сам предмет как историческая, психологическая, литературная реальность, хотя в природном, физическом смысле изучаемый человек или явление существует самостоятельно, независимо от оценки, физически реально. Об объективности существования гуманитарного предмета можно говорить лишь в том смысле, что исследователь имеет право данный дискурс или теорию рассматривать как независимо от его исследования сложившуюся реальность, требующую изучения, а не реконструкции.

Таким образом, мы считаем, что гуманитарные теории по своим формальным признакам аналогичны естественнонаучным теориям, но в то же время имеют специфические особенности, в частности нарративную объяснительную способность и большие конструктивные возможности, позволяющие им конструировать не только объект, но и предмет теории.

\section{1 Литература}

[1] Афанасьев А.И. Субъект объяснения как компонент объяснительного процесса // Філософські пошуки. Вип. XVII. - Львів-Одеса: Cogito-Центр Європи, 2004. - С. 353-361.

[2] Бахтин M.M. Формы времени и хронотопа в романе: Очерк по исторической поэтике // Бахтин М.M. Вопросы литературы и эстетики. - М.: Художественная литература, 1975. - С. 234-407. 
[3] Гр.язнов Б.С., Дынин Б.С., Никитин Е.П. Теория и ее объект. М.: Наука, 1973.

[4] Дынин Б.С. Метод и теория.-М.: Знание, 1968.

[5] Костюк B.H. Методология научного исследования-КиевОдесса: Вища школа, 1976.

[6] Лотман Ю.М. В школе поэтического слова: Пушкин, Лермонтов, Гоголь: Кн. для учителя. - М.: Просвещение, 1988.

[7] Французская семиотика: от структурализма к постструктурализму. - М.: Прогресс, 2000.

[8] Харре P. Социальная эпистемология: передача знания посредством речи // Вопросы философии. - 1992. - Na 9. - С. 49-62.

[9] Хюбнер К. Критика научного разума. - М.: ИФРАН, 1994.

[10] Эйхенбаум Б.М. Теория «формального метода» // Эйхенбаум Б.М. О литературе.-М.: Советский писатель, 1987. - С. 375-408.

[11] Эпштейн М.Н. Культуроника: технология гуманитарных наук / http://www.topos.ru/articles/0410/04_08.shtml. 